\title{
Entre la unidad y la pluralidad. El concepto de partido-facción en el Perú 1770-1870
}

Entre l'unité et la pluralité. Le concept de parti-faction au Pérou, 1770-1870

Between Unity and plurality. The concept of Party-Faction in Peru (1770-1870)

\section{Cristóbal Aljovín de Losada}

\section{OpenEdition}

Journals

Edición electrónica

URL: http://journals.openedition.org/bifea/2117

DOI: $10.4000 /$ bifea. 2117

ISSN: 2076-5827

Editor

Institut Français d'Études Andines

Edición impresa

Fecha de publicación: 1 abril 2010

Paginación: 63-84

ISSN: 0303-7495

Referencia electrónica

Cristóbal Aljovín de Losada, «Entre la unidad y la pluralidad. El concepto de partido-facción en el Perú 1770-1870 », Bulletin de l'Institut français d'études andines [En línea], 39 (1) | 2010, Publicado el 01 octubre 2010, consultado el 06 noviembre 2020. URL : http://journals.openedition.org/bifea/2117 ; DOI : https://doi.org/10.4000/bifea.2117

\section{(c) $(1)$}

Les contenus du Bulletin de l'Institut français d'études andines sont mis à disposition selon les termes de la licence Creative Commons Attribution - Pas d'Utilisation Commerciale - Pas de Modification 4.0 International. 


\title{
Entre la unidad y la pluralidad El concepto de partido-facción en el Perú 1770-1870
}

\author{
Cristóbal Aljovín de Losada*
}

\begin{abstract}
Resumen
El artículo busca comprender las mutaciones semánticas del concepto partido-facción. La cultura política ha variado respecto de cómo se perciben los grupos u organizaciones políticas. Para comprender las mutaciones semánticas de «partido» y «facción», se debe observar bajo qué ideales se imagina la política. En los tiempos virreinales, «partido» estaba circunscrito al mundo de la corte, de las rencillas burocráticas, gremiales y, de otro lado, «facción» a los tiempos de rebeliones. A partir de las Cortes de Cádiz, el lenguaje constitucional transforma el vocabulario político. Es una trasformación que se acelera con el ingreso del republicanismo en la década de 1820. Se añaden nuevos estratos de contenido a «partido», vinculados a los conceptos de soberanía y pueblo sin que ellos sean mencionados directamente.
\end{abstract}

Palabras clave: Perú, partido, facción, democracia, cultura política, conceptos políticos

\section{Entre l'unité et la pluralité. Le concept de parti-faction au Pérou, 1770-1870}

\section{Résumé}

Cet article souhaite mettre en évidence les mutations sémantiques du concept de parti-faction. La culture politique a modifié sa perception des groupes ou les organizations politiques. Pour saisir les mutations sémantiques de «parti» et de «faction», il faut considérer les imaginaires qui meuvent la politique. Sous la vice-royauté la notion de «parti» était réservée au monde de la Cour, aux querelles entre administrations et corps de métiers. De son côté, la notion de «faction » renvoyait aux époques 
de troubles. À partir des Cortés de Cadix le language constitutionnel modifie le vocabulaire politique, transformation qui s'accélère au début des annés 1820 avec l'avènement du républicanisme. La notion de «parti» s'élargit, intégrant des éléments de sens, liés aux concepts de souveraineté et de peuple sans que ceux-ci ne soient directement mentionnés.

Mots clés : Pérou, parti, faction, démocratie, culture politique, concepts politiques

\section{Between Unity and plurality. The concept of Party-Faction in Peru (1770-1870)}

\section{Abstract}

This article aims at understanding how the "Party/Faction" concept was inserted in the political language of the Constitutional Monarchy on the eve of the Republic. To that end, we study this pair of concepts in relation to the political culture between the end of the viceroyalty until the early republic circa 1870 The article emphasizes the relationship between the acceptance of parties and a political culture based on either unanimity or plurality, or a combination of the two.

Key Words: Peru, party, faction, democracy, political culture, political concepts

\section{INTRODUCCIÓN}

En el siglo XIX, las referencias en torno a «partido» y «facción» son comunes en los textos políticos1. No puede comprenderse la política sin tomar en cuenta pugnas entre diferentes grupos de interés. Puede constatarse, sin embargo, que la cultura política relativa a la percepción social de estas organizaciones se transformó entre los tiempos virreinales y la República. Durante el Virreinato la voz «partido» estaba circunscrita al mundo de la Corte, de las rencillas burocráticas o gremiales: la voz «facción», por su parte, se reservaba en época análoga a los tiempos de revuelta o rebelión. En la literatura política española del siglo XVIII, partidos se circunscribían básicamente a una realidad política determinada: la inglesa; aunque paulatinamente se comenzó a mencionar también a Francia y a los Estados Unidos (Fernández Sarasola, 2000).

El vocabulario político se transforma a partir de las Cortes de Cádiz en un lenguaje constitucional y, en un inicio, de monarquía constitucional. Esta trasformación se acelera con el ingreso del republicanismo en la década de 1820: se añaden

1 Es importante mencionar que muchas de las referencias del presente artículo pertenecen al mundo urbano, sobre todo de Lima, sin embargo, los vinculos con el campo son fuertes. Uno de los destinatarios de los panfletos y debates políticos eran los miembros del ejército. De igual modo, la relación ciudad-campo era bastante fluida. Un segundo problema en torno a la expansión o a la democratización, para utilizar el vocabulario historico de R. Koselleck, del uso de dicho vocabulario es la cuestión del idioma. Un porcentaje muy alto de la población (indígenas) no hablaba español. entonces a «partido» nuevos estratos de contenido que aparecen vinculados a los conceptos de «soberanía», «representación», «nación», «pueblo» y «patria», entre otros, aunque esto no significa que estos términos sean mencionados directamente. Al concluir el virreinato, la dinámica política en el Perú cambió no solo por su condición de ser una entidad con una independencia absoluta frente a la antigua metrópoli sino porque adoptó el sistema republicano como forma de gobierno, lo que se ve reflejado en ambos términos. Partido/facción entraron al centro del debate político de modo muy conflictivo, y ambos sufrieron transformaciones sin que sus antiguos significados desaparecieran. Para comprender las mutaciones semánticas de «partido» y «facción» se debe observar bajo qué ideales se imagina la política.

La descripción presentada es parte de una transformación mayor del vocabulario político de Occidente. Los motores de los cambios están ubicados en diferentes partes, en especial en Europa. En líneas generales, la dinámica inglesa permitió una aceptación más rápida y mejor insertada de una concepción de la política basada en los intereses sociales y la dinámica de partidos de gobierno y de oposición que es propia del sistema parlamentario entre 1783 y 1832 (Gunn, 1971: 1-34; 1974). La Europa continental, en cambio, estuvo más marcada por el sentimiento de que la representación política debía buscar la unidad. Sin embargo, como se nota para el caso francés, la conformación social y las prácticas políticas empujaban lo político hacia una representación plural (cf. Rosavallon, 1998: 219-222). El Perú se insertó en esta última tradición.

Durante la república decimonónica «partido-facción» oscila entre dos extremos y variantes cruzados entre ellos. Se trata de transformaciones que se relacionan con los valores de la cultura política: una busca la unanimidad y otra se sustenta en el pluralismo; o, más acorde con la realidad histórica, una variedad de combinaciones entre ambas. En la primera mitad del siglo XIX predomina la idea de que la política debía expresar la unidad, la cohesión de la nación, mientras que los intereses y las diferencias se consideraban sospechosos. Bajo este esquema, la política se convierte en una suerte de suma cero: si uno gana, el otro pierde. No es posible concebir la política compuesta por un gobierno y una oposición. Vale la pena mencionar que hubo cuestionamientos a esta forma de imaginar la política desde muy temprano, aunque no participaron de ellos la mayoría de los «ciudadanos», que utilizaban más bien un lenguaje republicano bajo el principio de la unanimidad para imaginar la política. Este esquema general va cambiando durante la segunda mitad del siglo XIX. Se fomenta entonces el mundo de las asociaciones, de los clubes políticos y, posteriormente, el de los partidos como parte fundamental del juego republicano; esto último no implica que la búsqueda de la unidad hubiera entonces quedado sepultada. Es así como aparece una vida política concebida en términos plurales, y con actores políticos bien definidos (Aljovín, 2005); sin embargo, la búsqueda de la unanimidad no desaparece. Se conjuga con cierta diversidad.

Hay un punto importante que resaltar en las transformaciones semánticas de partido que no está necesariamente vinculado a la dicotomía unanimidad/pluralismo, 
que es algo difícil de percibir en una lectura rápida del uso del concepto. Es comprender el añadido al concepto de partido como un aparato/organización política, y no solamente como movimiento bajo un liderazgo y/o con un conjunto de ideas sobre el país o la política (el partido liberal, por ejemplo). Para Ulrich Mücke, a mediados de 1870, los miembros del partido civilista imaginaban su partido como una organización política más allá del líder del partido; aunque cabe mencionar que hay referencias anteriores a partidos políticos (Ulrich Mücke, por publicar).

Hay una diferencia importante entre los tiempos virreinales previos a las Cortes de Cádiz y la República. En el primer caso, era claro que la defensa de la unidad implicaba no romper con lo ya constituido, ligado a la lealtad al monarca y la Iglesia. La unidad remite a la armonía de lo diverso en una sociedad estamentaljerárquica: es la lealtad al padre, el rey, y a la verdad revelada, la Iglesia. Es por ello que la unidad se debe preservar y no crear, aunque no es por ello un mundo concebido de modo estático. Se concibe que hay cambios paulatinos bajo la tradición. En tiempos republicanos, en cambio, la unidad está vinculada a las nociones de un orden y una libertad que busca establecerse. Hay que recordar que el republicanismo es una concepción de la política basada en la voluntad. No hay un pasado que sirva de amparo; hay una nación, sin embargo, que busca ser representada por los ciudadanos virtuosos, por los verdaderos patriotas, y no por falsos patriotas enemigos de la nación que actúan bajo el comportamiento egoísta de mirar solo su interés individual. Estos últimos planteamientos, como ya mencionamos, van cambiando a mediados del siglo XIX.

\section{LOS DICCIONARIOS}

Es significativo revisar el diccionario de la Real Academia Española de 1780. El término «partido» tiene diez entradas, cinco de las cuales son de interés para el presente trabajo:

1.- «s.m. Parcialidad, o coligacion entre los que siguen una misma opinion, ó intereses. Factio, partes»;

2.- «Amparo, favor, ó proteccion particular de muchos; y así se dice: fulano tiene partido para el logro de tal pretension. Suffragium»;

3.- «En el juego se llama al conjunto, o agregado de varios que entran en él: como compañeros, contra otros tantos. Certatores in ludo singuli in singular, socii in ludo»;

4.- «El conjunto, ó agregado de personas que siguen y defienden una misma sentencia, opinión, o dogma. Sectarii, nostrates»;

5.- «Interes, ó razon de propia conveniencia; y asi se dice: Defender su partidario. Partes suae».

Las entradas de «partido» en los diccionarios de la Real Academia Española entre los años 1780 y 1884 son muy similares. No hay una nueva definición, lo que corresponde con la imagen de un término congelado en el tiempo.
Dichos diccionarios han tenido dificultad para añadir los nuevos significados del vocabulario político. Para la segunda mitad del siglo XIX, en contra de lo que se podría esperar, la entrada «partido político» no existe. Esto resulta extraño, teniendo en cuenta la gran dinámica electoral del siglo XIX hispanoamericano (Annino, 1995). Repensando las definiciones registradas, «partido» es un término que aparece asociado de manera constante con la idea de división; aparece como un grupo humano que se vincula respecto de algo con el fin de lograrlo. Es importante subrayar que «partido» no tiene carga negativa; por el contrario, «tomar partido» se entiende como una parte de la vida. En las entradas de los diccionarios, «partido» no implica romper la unidad del sistema político; las definiciones de «partido» al menos, no parecen describirlo así. Es en el uso de concepto de partido que aparece la carga negativa, esto es, de grupos de personas que buscan romper la unidad política.

El Diccionario del Pueblo (1855) de Juan Espinosa, publicado en Lima, en cambio, tiene definiciones más acordes con los tiempos. El Diccionario del Pueblo es un libro de combate político, como su propio título lo sugiere. Espinosa titulaba su obra también Diccionario Republicano por un Soldado. Es normal que un diccionario como el de Espinosa tenga entradas más «políticas» que los de la Real Academia. En el caso de Espinosa, este muestra una actitud ambivalente frente a los «partidos políticos» reflejando los cambios de la semántica política de la segunda mitad del novecientos. Los partidos son:

«utilísima cosa cuando hay dos en un pueblo, que se vigilan mutuamente y que pretenden ser cada uno el único capaz de hacer la felicidad de todos los asociados».

En un escenario favorable al sistema de partidos, Espinosa concibe la pugna partidaria como un debate ideológico. Los partidos buscan «cada teoría o principio profesado lo mejor que tiene respecto a otro, acábase por encontrar muchas cosas útiles a la sociedad». Espinosa en cambio considera nefastos los partidos «en que se dividen los pueblos» que «son meramente personales». Estos partidos solo producen «perjuicios... ya no se sostienen doctrinas que prometan mas o menos bienestar». Se trataría de una maquinaria de dominación a través de la «estupidez del espíritu de partido; puesto que para un partidario fervoroso, la única recomendación que vale es la de ser del partido». Están bajo el yugo del partido. Se termina en una sociedad donde «no hay leyes, ni garantías ni seguridad de ninguna especie; todo es confusión, rapiña, y violencias».

Otra es la historia de «facción». Veamos las entradas del diccionario de la RAE de 1780 que nos interesan:

1.- «Acometimiento de soldados, o execucion de alguna empresa militar, para ganar gloria y honra contra los enemigos. Faccinus»;

2.- «Parcialidad de gente amotinada y rebelada. Secta, turba, tumultuaria, caterva»;

3.- «Qualquier parcialidad, o bando de personas unidas en una comunidad, Factio, partes». 
Si se revisa la entrada «faccioso»: encontramos «SA. adj. inquieto, revoltoso, perturbador de la paz y quietud pública. Factiosus». En las entradas que hemos leído, facción implica división, romper el orden establecido. Es definida muchas veces con una fuerte carga negativa. No hay neutralidad al definirla. Tiene una fuerte connotación de violencia política que busca romper con la legalidad. Es el grupo humano que busca destruir el orden e imponer el desorden. Su relación con desorden muestra una concepción peyorativa del término. Vale la pena resaltar que orden es un concepto fuertemente positivo desde cualquier perspectiva política (monárquica absolutista o constitucional, republicana entre otras).

En las otras entradas de los diccionarios decimonónicos se incrementa la visión negativa de facción. Quizá sea una reacción al convulsionado siglo XIX hispanoamericano. Veamos el diccionario de la Real Academia Española de 1843:

1.- «f. Acción militar. La parcialidad de gente amotinada o rebelada, Sedidiosus coetus»;

2.- «Bando, pandilla, parcialidad o de partido en las comunidades o cuerpos. Factio, partes».

«Facción» tiene en común con «partido» implicar división. En las entradas mencionadas, «facción» arrastra una fuerte carga negativa de acción militar. Facción usualmente se entiende como un grupo humano que comete actos violentos en contra de la legalidad. Como veremos, esta visión de facción se repite en los documentos. A diferencia del partido, la facción suele actuar de modo ilegítimo. Ningún grupo se tilda de facción. Son los contrincantes los que se refieren así a sus adversarios.

\section{A FINES DEL VIRREINATO}

Durante el Virreinato hay una clara visión de la importancia de mantener la unidad en torno a la figura del rey y la religión; en el primer caso, para conservar la relación de vasallaje, en el segundo, para ser un buen católico. De igual modo se fomenta la unidad en otras esferas. En el Mercurio Peruano hay un conjunto de artículos, por ejemplo, que alaban la unidad en el plano ideológico. En un artículo del Mercurio Peruano la "Academia de San Marcos y a los ingenios del Perú" han depuesto "todo espíritu de partido". Es un logro alabado, según el articulista, por extranjeros. Es una virtud que los caracteriza (Mercurio Peruano, 17 de julio de 1791, tomo II: 204). En otro artículo, se fomenta una cultura crítica a través del debate. Se teme, sin embargo, que la elocuencia oculte la verdad:

«La verdad no nace de los choques de la opinión: no habita entre los sofismas agudos de la controversia, del juridiscente o del metafísico; huye siempre de los partidarios, de los verbosos y aun a menudo de los eloquentes» (EI Mercurio Peruano, 11 de agosto de 1791, tomo II: 266-267).

En el plano político, en tiempos de paz (no de revueltas y rebeliones), no es tan fácil percibir la alabanza a la unidad. El Perú era un Virreinato y no el corazón del Imperio Español. La Monarquía Hispana, sin embargo, se sustentaba en un conjunto de sentimientos y vínculos hacia el rey que eran compartidos en el Perú.
La imagen de la Monarquía en general en el siglo XVIII es la de una suerte de gran familia en la que la figura del monarca creaba sentimientos de filiación con los vasallos. En ese sentido, es primordial honrar al padre; es decir, al rey. En este sentido podemos citar un artículo del Mercurio Peruano; en éste se describe la diferencia entre los salvajes y los europeos. Los primeros no fomentan los vínculos filiales y viven marcados por una cultura de la facción. En cambio, los europeos son lo contrario:

«el Padre Olavarrieta da a entender que los peruanos son unos salvajes recién- conquistados, y procura hacer revivir el espíritu de facción, que se halla apagado hasta el punto de que europeos y americanos nos miramos todos como hijos de un mismo padre» (EI Mercurio Peruano, 17 de julio de 1791, t. II: 133).

Respecto de la Monarquía y la imagen del monarca, es interesante la explicación de los seguidores del Virrey en torno a la Gran Rebelión, la liderada por Túpac Amaru II, entre 1780 y 1781. Estos explican con terror cómo un grupo de facciosos han roto los lazos de unidad con la Monarquía Hispana y el rey; por lo tanto, no cumplen sus funciones de buenos vasallos. También cometen actos sacrílegos, es decir, no hay respeto por la religión. Esta visión está graficada en la documentación del obispo del Cuzco, Juan Manuel de Moscoso y Peralta. Moscoso condena la Gran Rebelión a los pocos días del ajusticiamiento del Corregidor Antonio de Arriaga, considerado por la historiografía como el día en que estalló ese movimiento rebelde. En una carta al virrey Jáuregui del 17 de noviembre de 1780, el religioso describe el liderazgo de Túpac Amaru como el de «un indio rebelde, y enteramente abandonado a los mas execrables delitos... que sus influjos, pésimo ejemplo y perversas sugestiones, se ha engrosado la facción» (CDIP, 1971, Tomo II, Vol. 2: 285). Como eclesiástico, el obispo otorga el mayor castigo que puede imponer al cacique Túpac Amaru II y a sus seguidores: la excomunión. Las razones son terribles:

«por incendiario de capillas públicas y de la iglesia de Sangarara... por rebelde traidor al Rey, Nuestro Señor» (CDIP, 1971, Cedulón de Excomunión de Túpac Amaru por Juan Manuel Moscoso, 17/11/1780 Tomo II, Vol. 2: 275).

Con la excomunión, Túpac Amaru deja de pertenecer a la comunidad católica. De igual modo, ordena a los religiosos que «diesen a entender a los fieles, en púlpitos y conferencias, la obligación que tienen de mantenerse obedientes al monarca, no entrando en la criminosa facción; les hice presente sus deberes de tomar, en este caso, las armas todos los eclesiásticos para resistir al rebelde...» (CDIP, 1971, Tomo II, Vol. 2, 285).

\section{LAS CORTES DE CÁDIZ}

El lenguaje constitucional de las Cortes de Cádiz fue el inicio de un cambio profundo del mundo hispanoamericano, sobre todo en países como el Perú y México, con una independencia tardía en comparación a la del Río de la Plata. 
Para la voz partido-facción en España, Luis Fernández Torres tiene interesantes opiniones porque da razón de la concepción negativa de los términos y de su uso poco frecuente a inicios del novecientos. La historiografía registra tres lenguajes políticos en que se puede clasificar el discurso político de las Cortes de Cádiz: el histórico, el absolutista y el liberal o moderno. El primero apunta a regresar a un sistema, el vigente antes de la dinastía borbónica, en que las Cortes de los diferentes reinos o ciudades del Imperio recuperen sus funciones políticas. El segundo añora el gobierno de los últimos reyes borbónicos; y el tercero plantea que la soberanía reside en el pueblo. Ninguno de los tres se prestaba a una visión plural de la política. Dichos lenguajes estaban concebidos en términos de una visión unitaria de la política o bien la tradición escolástica del bonum commune que puede ser fácilmente confundido con la idea de voluntad general de Rousseau; además los hechos de la Revolución Francesa no eran un buen ejemplo. Partido se asocia, por esto último, a anarquía; aunque, en la segunda mitad de la década de 1810, un grupo de liberales exiliados utilizan partido de modo positivo (Fernández Torres, 2009).

En el Perú, sobre todo durante la administración del virrey José de Abascal (18061816), se tiende una política de represión frente a los rebeldes (la formación de las Juntas de gobierno en Chuquisaca, Santiago de Chile y las dos de Quito, entre otras) $y$, de igual modo, se busca crear una imagen de unidad, de concordia. Abascal, a quien los historiadores consideran el artífice de que el virreinato del Perú fuera el centro de la contrarrevolución en la década de 1810, funda el «Regimiento de la concordia española del Perú, para que unidos fraternalmente europeos y americanos se disipen rivalidades perjudiciales e impropias entre vasallos de un mismo soberano y que componen una misma nación con iguales intereses y obligaciones» (cf. Porras, 1974: 168); es decir que hay un fuerte discurso de unidad frente a la desunión. El discurso del elector Ángel Luque a los miembros del Cabildo explica muy bien la política del virrey Abascal: una lucha contra una cultura del partido. El regimiento de la Concordia y las elecciones de la asamblea muestran un cambio favorable en camino a la unión:

«Nuestra seguridad que era pequeña ha crecido con la Concordia de esos voluntarios distinguidos que la componen, y ha desaparecido esa necia rivalidad de hijos y padres, esa rivalidad entre hermanos de una misma tribu de una misma familia. Crecerá también nuestra seguridad con la Concordia de la presente asamblea electoral. Fuera pues de nosotros esa necia rivalidad de samaritanos y judíos, como si fuésemos ese tosco pueblo: esa necia rivalidad del partido del hombre no formado, y acostumbrado a no ser más que un solo color, esa necia rivalidad de la turba del bajo pueblo que en el carácter del ciudadano, en su probidad, en sus costumbres no encuentra el mérito que encuentra la razón, la sensatez, el clamor general de la naturaleza» (Gaceta del Gobierno de Lima. 16 /XII/1812: 767-768)

Veamos algunos ejemplos recopilados en torno a la Rebelión de los hermanos Angulo y del curaca Mateo Pumacahua en la ciudad del Cuzco el año 1814. Ésta se expandió militarmente en el sur andino y sus redes alcanzaron el Buenos Aires revolucionario. A diferencia de la Gran Rebelión de Túpac Amaru entre los años 1780-1781, la rebelión de 1814 tuvo un liderazgo multiétnico (indios, mestizos y criollos) y de diferentes categorías de personas (curacas, abogados, sacerdotes, entre otros). Los protagonistas están aprendiendo un nuevo vocabulario político originado por los debates en torno a la Corte y la Constitución y, de igual modo, del revolucionario Río de la Plata (O'Phelan, 1985); de acuerdo a los realistas, sin embargo, Pumacahua era reconocido como Inca por los indios. En un informe de la Real Audiencia del Cuzco del año 1815, se explica cómo las autoridades no actuaron con decisión en reprimir a los cabecillas en un inicio:

«de modo que tuvieron tiempo y preparación para formar el plan que ejecutaron la noche del 2 al 3 de agosto, embriagando antes la tropa, e interesando en su facción a varios de los oficiales, haciendo de jefes en este infame atentado Gabriel Bejar, José Angulo y Manuel Mendoza, decapitados ya en el día todos tres; los que pusieron al principio a este público en una opresión que apenas tuvo libertad para deliberar sobre

el partido que debía abrazar en esta tan inesperada como violenta crisis» (CDIP, 1971, tomo III: 117-118).

Según los informes de la Real Audiencia del Cuzco, los rebeldes son descritos como una facción carente de apoyo del pueblo; es decir, no es el pueblo ni lo representa. Facción implica de modo implícito o explícito una definición de quiénes componían el pueblo. Para los documentos realistas, los rebeldes eran la chusma:

«bandidos bien pagados y algunos de ellos buscados y animados por el escribano José Agustín Becerra (quién murió en un cadalso), sus hijos y secuaces, según sabíamos, para que a voces pidieran nuestras cabezas, y a esta representación cómica bautizaban con el título de aclamación» (CDIP, 1971, tomo III: 173).

Se infiere de la cita una lucha de palabras para dar legitimidad a los rebeldes o quitársela. La Real Audiencia duda del carácter de la Rebelión, del apoyo de pueblo, y de la aclamación. En estas largas citas de la Real Audiencia del Cuzco se nota cómo facción tiene un carácter negativo y opuesto a «pueblo». A pesar de que sean eventos que ocurrieron con posterioridad a la Constitución de Cádiz, es difícil definir de qué tipo de pueblo se trata: si éste es soberano o no. Lo que es claro, en cambio, es que la facción no es parte de él.

La facción revolucionaria, de acuerdo a la Real Audiencia, se compone de chusma, gente equivocada o mediocre. Los rebeldes eran:

«ignorantes, sin la menor instrucción en ninguna materia, sin saber más que odiar a los europeos y al gobierno español; las clases de éstos eran humildes, porque Pumacahua era indio neto elevado a la clase de brigadier por los servicios que había hecho a la corona en tiempo del rebelde Tupac Amaru; los Angulo y Béjar mestizos, Hurtado de Mendoza natural de Santa Fe de Corrientes en el Virreinato de Buenos Aires, blanco pero de clase ordinaria; muy pobres todos, hasta no tener qué comer, a excepción de Pumacahua que en clase de indio le sobraba proporciones; todos muy 
cobardes, menos Hurtado que era naturalmente turbulento» (CDIP, 1971, tomo III: 262, 263).

En pocas palabras, gente menospreciable.

Es comprensible que se desarrolle un fuerte discurso respecto a la unidad en tiempos de rebelión; sin embargo, dicha concepción se extiende para comprender la política. Una de las experiencias nuevas vinculadas a las Cortes de Cádiz fueron las elecciones en las cuales los ciudadanos debían participar. Previamente, hubieron elecciones para la convocatoria de las Cortes que se restringía a los miembros de los cabildos. Es con las Cortes que las elecciones se vuelcan a las «calles» y comienza una dinámica electoral de captura del voto ciudadano. En este contexto se da lugar a una crítica por la participación de los malos elementos de la sociedad, que fomentan la discordia. Bajo esta lógica, las elecciones corren el peligro de elegir representantes entre los sectores menos esclarecidos de la sociedad. En el suplemento de El Investigador del 18 de diciembre de 1813 se reflexionaba del siguiente modo:

«¿No estamos ya convencidos de que no hay superioridad entre el criollo y el europeo? ¿No somos todos iguales? .... ¿ ¿No hay entre ellos individuos respetables, y beneméritos por su bondad, probidad, talento y circunstancias, como los hay entre los americanos? Pero parece que la ilustración y decantada libertad civil a que hemos llegado en el día, es a la de poner delante de nuestros ojos, unos representantes arrancados de los talleres, y unos individuos, que sólo por una siniestra intención pudiera exponerlos al vituperio, y escándalo de todo los que tengan un rasgo de luz natural. Sin principios, sin educación, sin conocimientos, ellos no son más que unos instrumentos de aquél por cuya mano vienen guiados.

¿Qué ilustración, qué fomento, qué felicidad nos proporcionarán unos hombres que ignoran lo que han sido, lo que son, y lo que van a ser? Esos espíritus de partido que tan indecorosamente se manifiestan, y que con tanto deshonor nuestro fomentan la ceguedad e inercia del miserable vulgo, mejor sería que lejos de atraer a su patria, las desgracias, el desconsuelo, la indigencia, y el vilipendio, se emplease en manifestar a cada uno su verdadero interés, puesto que de otro modo, ni son ni han de ser jamás sino unos miserables que encenegados en su fanatismo, estarán siempre al sueldo de aquél cuya armonía detestan».

\section{DE LA INDEPENDENCIA A 1850}

El lenguaje político de la Independencia fomenta la noción de unidad. Hay una primera explicación para ello: las propias circunstancias de la guerra de emancipación (1820-1824). Esta refuerza la idea de unidad en ambos bandos, el patriota y el realista; sin embargo, la historia fáctica de la guerra de Independencia es un conjunto de traiciones y de posiciones encontradas. Hay que recordar que los cambios de bando, tanto en la oficialidad como en la tropa, constituyen pieza clave para comprender el devenir de la guerra. Es interesante notar que buena parte de los oficiales del ejército peruano posterior a la batalla de Ayacucho, en 1824, pertenecieron al ejército realista y su tropa estuvo compuesta de indios quechua-hablantes (Riva-Agüero, 1969: 151-162). Continuando con el tema de la unidad, por el lado realista, por ejemplo, hay un reclamo de que a «los españoles americanos les conviene unirse con la patria común, porque ésta los defiende y asegura de enemigos exteriores y consolida la paz interior». Los hombres buscan «su bienestar, su tranquilidad y la felicidad» y la forma de conseguirlo en América es en comunión con el rey. A final de cuentas, americanos y españoles «somos una misma familia, la localidad del nacimiento no debe influir en los resentimientos personales ni perjudicar la causa pública» (Observaciones sobre los perjuicios que causaría la independencia a las Américas Españolas /Fernando Cacho, n. ${ }^{\circ} 33: 3$, martes 5 de junio de 1821).

El clamor por la unidad va más allá de la demanda por aunar fuerzas ante un enemigo común, entendible en circunstancias de guerra. Se trata de una concepción de la política que crea el requerimiento de extraer un consenso común, criticando en cambio la concepción de la política como un juego de intereses. El juego de intereses es considerado bajo esta perspectiva como un corruptor de la República. Este lenguaje se observa con claridad en los debates públicos en torno a la política y al régimen que se debía establecer durante el protectorado de José de San Martín (1821-1822) y en los regímenes posteriores. Para La Abeja Republicana, publicación que defendió el sistema republicano, existe el peligro de que las pasiones dominen la situación. Dichas pasiones se incrementan en momentos de luchas partidarias, pues éstas crean las condiciones para el desarrollo de la codicia de los líderes. Es peligroso cuando el pueblo, «arrastrado por los partidos opuestos, cree lanzarse hacia el objeto de sus esperanzas». Los ejemplos de la historia muestran el precio que pagan las repúblicas por la lucha entre partidos. Es el camino hacia la tiranía «bajo el estandarte de la intriga». Hay ejemplos, entre ellos «el combate ya por Pompeyo, ya por César, y jamás por sí mismo... no hace sino mudar de mano: al silencio de las tumbas, que produce el despotismo, sigue el ruido de las facciones» (La Abeja republicana, n. ${ }^{\circ} 2$, jueves 9 de agosto de 1822: 15-16)

Uno de los grandes clamores del debate político era el requisito de crear un orden con libertad. Es un tema recurrente. Hay una vasta literatura que reflexiona sobre lo ocurrido en la Francia posterior a 1789, y en los países hispanoamericanos después de 1808. Ambas experiencias, la francesa y la hispanoamericana, han sido marcadas por la anarquía política y el despotismo. Es por ello que se da la búsqueda de un orden constitucional que evite el «espíritu de partido». Para un autor de un artículo de la Abeja Republicana del 7 de noviembre de 1822, «las repúblicas que no son regidas por federación» pierden «poderío y esplendor»; y, aún peor, «un ciudadano ambicioso» tiene las posibilidades de fomentar «el espíritu de partido so color de patriotismo». El artículo considera que hay algo innato que lleva al hombre a ser partícipe del «espíritu de partido». Entonces, la Constitución debe crear leyes sabias que lo obstaculicen, siendo la solución, para el autor de la carta, una república federativa (La Abeja Republicana, «Carta remitida/ Firma $M N »$, n. $^{\circ} 28$, jueves 7 de noviembre de 1822: 254-255). La 
mencionada propuesta federalista no tenía una masa crítica importante. Dicho sea de paso, el federalismo fue una posición ideológica poco aceptada en el Perú en comparación con el resto de los países hispanoamericanos (Loayza \& Aljovín, 2009: 517-524).

En toda la primera mitad del siglo XIX se nota una fuerte crítica a los partidos $y$, sobre todo, a las facciones. Para muchos, éstos crean pasiones que terminan en la anarquía, en la sinrazón del conflicto político. Los partidos/facciones eran percibidos como grupos sociales que buscaban su provecho propio y no el de la nación. Eran antipatriotas. Es interesante notar que, a inicios de la República no había organizaciones políticas públicas como tales; es decir, con alguna formalidad. Obviamente, en momentos álgidos, como durante los golpes de Estado, los grupos políticos de algún modo se definían. Ser patriotas era lo que sobresalía cuando se definían a sí mismos; es decir, eran los representantes de la nación, del conjunto de la sociedad. Felipe Pardo y Aliaga fue un escritor muy crítico de un sistema republicano igualitario, al que acusaba de tender hacia la anarquía. Pardo se calificaba a sí mismo como defensor del orden; su propuesta era fundar una república de notables, de pocos electores, aunque no defiende, al menos públicamente, el establecimiento de una monarquía. Pardo asocia los partidos con las pasiones y la anarquía. En 1834 escribe un poema satírico titulado Las abejas y el zángano sarnoso en que define «partido» del siguiente modo:

«Se entronizó la anarquía

Y en laberintos eternos

Los partidos, las pasiones,

A la colmena pusieron»

(Pardo y Aliaga, 1973: 361).

En el Mercurio Peruano de la década de 1820, como en muchos periódicos de la época, hay discusiones teórico-prácticas sobre el sistema republicano. Hay un afán por definir la cuestión ideológica. El editorial del 31 de diciembre de 1827 busca «combatir los sofismas de las facciones... repeler calumnias y ultrajes de los extranjeros que pretenden dividirnos para dominarnos». Estas facciones buscan «desacreditar los patriotas esfuerzos». En cambio, los patriotas «no ha sido guiado por otro interés que el de la libertad racional de sus ciudadanos, apoyado sobre el orden, la moderación y la religiosa observación de la constitución». De un modo sugerente este editorial muestra una retórica de combate político opuesto a las facciones; argumenta que éstas destruyen los cimientos de unidad de la República. En el caso del artículo citado, a las facciones se las ubica en círculos de extranjeros con poder. Hay que mencionar que muchos de los oficiales de los ejércitos libertadores de los generales José de San Martín y Simón Bolívar fueron incorporados al ejército peruano, llegando a ocupar cargos importantes. Muchos oficiales peruanos consideraban tener derecho sobre los cargos que ellos detentaban (Aljovín, 2000, cap. 4). En este debate, se nota cómo la crítica contra un «partido» $\mathrm{O}$ «facción» no solo refleja una postura ideológica a favor a la unidad, sino también constituye un argumento retórico para luchas concretas. Es un concepto que se politiza rápidamente.
En 1828, Manuel Lorenzo Vidaurre, uno de los grandes juristas de la época, polémico, egocéntrico y con una típica concepción jurídica-política social de transición, publicó un libro con un título intrigante: Efectos de las facciones en los gobiernos. En este libro se recopilan los principios fundamentales del gobierno democrático constitucional representativo. Para el tema del presente artículo, el libro de más de 200 páginas promete más de lo que aporta. En verdad, el título es intrigante y se requiere comprender qué quiere decir el autor. Esta compilación de folletos, en la mayoría escritos por Vidaurre, es una defensa de la acusación de complot político a Vidaurre en contra de José La Mar, quien termina en el exilio, según él, por tercera vez. Dice Vidaurre que sus enemigos han planteado dicha acusación por su postura de que no se ofrezca la ciudadanía a los españoles en la nueva constitución. ¿Cómo se explica el título? No hay muchas referencias a partido o facción. La clave del título está en el último panfleto: Representación al congreso constitucional en que se trata de las principales cuestiones de derecho público constitucional. En este panfleto, Vidaurre acusa a sus enemigos personales Francisco Javier Mariátegui y Francisco Xavier Luna Pizarro de ser miembros de una facción que busca su alejamiento de la política. Se describe a sí mismo como un ciudadano ilustrado, patriota, congresista y presidente de la Corte Suprema. De modo muy sutil, no expresamente, contrapone a los pertenecientes a la facción a los patriotas-ciudadanos.

El fervor por la unidad no implicó una cerrazón frente al concepto de partido. Hay dos razones para ello. Una de orden fáctico: la política siempre implica la lucha de un grupo contra otro. En consonancia con esto, «partido» se comprende como el conjunto de los seguidores de un líder o un grupo de ideas. En las descripciones de pugnas políticas, se menciona cómo varios partidos participan en la política. Pongamos algunos ejemplos de la prensa: en 1843, en plena guerra civil, el oficial del ejército Manuel Guarda felicita al general Manuel Ignacio de Vivanco por ser el «señalado por el dedo de la opinión como el único digno de acaudillar un partido que anima ninguna de las miras bastardas que han animado a casi todos nuestros bandos civiles» (El Faro, «A la República», n. ${ }^{\circ} 10,25$ de febrero de 1843). La existencia de grupos políticos, partidos definidos como grupos que siguen a algún líder, generó algo de debate. Algunas de las preguntas de orden teórico giraban en torno a cómo definir qué partido «refleja la opinión pública». Para El Observador del año 1833, la respuesta es sencilla e implica una visión excluyente en la práctica de la política: «Basta saber si representa la parte sana de la sociedad» (El Observador, «elecciones», n. ${ }^{\circ}$ 7, 30 de enero de 1833).

El segundo factor es de orden ideológico. El gobierno representativo implica un sistema parlamentario, debate público, posiciones encontradas. Por otra parte, la lectura política no se restringía a autores del continente europeo (franceses, italianos, alemanes y españoles) y se nota, más bien, una cierta influencia del mundo anglosajón, que acepta el rol de los intereses en el mundo político. En $E$ Telégrafo de Lima hubo un debate en torno a las bondades de los partidos. Según este periódico, todo gobierno se enfrenta a contiendas, la política está marcada por el enfrentamiento y es un continuo movimiento de ataque y defensa. En este sentido, un gobierno nacional «debe constituirse en que este partido que haga su 
apoyo, extienda su base lo más que sea posible en la masa nacional, y profundice sus raíces en el pueblo por toda la periferia del Estado». Si el gobierno fracasa en este cometido, su caída está cerca.

Siguiendo el artículo reseñado, este manifiesta que es una ley de la sociedad el que una «porción» de ésta represente la «opinión nacional». La opinión se construye de «fracciones de las cuales cada una representa una opinión, unos intereses opuestos a la opinión e interés que defienden las demás». La meta del partido del gobierno es ser «el más numeroso... cuenta hombres de todas clases y profesiones, y... superioridades sociales». Entonces «el gobierno goza de nacionalidad, en despecho de los partidos que le declaran la guerra en sostenimientos de otros intereses». El partido nacional es el que logra reunir mayor número y calidad de personas que lo apoyan; es decir, una mezcla de inclusión y exclusión social (El Telégrafo de Lima, «Variedades: Debe un partido ser gobierno», 26 de enero de 1826). El gobierno es definido, por lo tanto, como el representante de la mayoría y no del conjunto de la sociedad. En un punto intermedio está un artículo de la Crónica política y literaria de Lima del 4 de junio de 1827. En este periódico se sostiene que el gobierno debe ser nacional y no debe estar vinculado a un partido. Reconoce sin embargo que «se formarán partidos, porque no todos los hombres convienen nunca en la misma doctrina; pero serán partidos de hombres libres, que desdeñan las tinieblas y menosprecian la seducción...»; es decir, se considera que se reconoce como parte del sistema político el debate de opiniones encontradas en un diálogo racional. Es como si los partidos formaran parte de la opinión pública y no del gobierno. Se requiere aquí de algunas precisiones. En primer lugar, la aceptación de «partido» está concebida más en el debate de opinión pública o de las personas influenciadas por el mundo intelectual anglosajón. Sin embargo, la mayoría de los textos de los periódicos tiene una aversión por el «espíritu de partido». Como planteaba El Voto Nacional, se debía buscar conformar «una asamblea nacional compuesta de ciudadanos libremente elegidos en la calma de las pasiones y extraños a los partidos» (El Voto Nacional, n. ${ }^{\circ}$ 91, 28 de febrero de 1835). El Republicano clamaba que «acállense las aspiraciones mezquinas, sustitúyase al espíritu de partido, el espíritu patrio, haya primero la patria, y ella sola por sus representantes» (El Republicano, 22 de enero de 1842).

Entre 1827 y 1850 , el sistema político peruano está lleno de turbulencias revolucionarias e intentos de golpe de Estado. El primer gobierno de Agustín Gamarra, entre 1827 y 1833, fue una interminable seguidilla de complots e intentos de golpe de Estado. Sobrevivió a diecisiete rebeliones, ocho de las cuales se dieron en 1833, durante su último año en la presidencia (Basadre, 1983, Vol. I: 278). Gamarra terminó desconfiando de todos, inclusive de los más cercanos a él. La descripción que el cónsul francés $M$. Barrère hiciera del comportamiento seguido por el presidente Gamarra en 1833 es aterradora. Ante las continuas rebeliones y atentados, Gamarra había perdido la confianza en sus más cercanos allegados, por lo cual había exiliado y acusado a muchos inocentes y vivía temeroso de los atentados contra su vida, lo que le hizo reducir sus salidas de palacio de gobierno. La lealtad política no era la norma, y los cambios de bando en cambio eran algo común (Aljovín, 2000, cap. 6).
¿Cómo se justificaban las revoluciones o los golpes de Estado? Responder esta pregunta nos puede ayudar a comprender los conceptos de «partido» y «facción». Hay un conjunto de justificaciones comunes a muchos de los intentos revolucionarios. Hay una imagen que se repite constantemente: el gobierno de turno representa un partido o una facción - es el término más común- ajeno a los intereses nacionales. Muchas de las revoluciones eran justificadas por la lucha contra el binomio partido/facción e intereses personales. Hay una relación directa entre partido/facción y la búsqueda del bienestar común; es decir, se derrocaba el gobierno de turno porque sus miembros estaban poseídos por pasiones egoístas; no estaban interesados por el bienestar nacional. No eran patriotas. El patriota estaba al servicio de la nación (Aljovín, 2000, cap. 6). Eso se nota con claridad por ejemplo en las explicaciones ofrecidas para legitimar el golpe de Estado de Agustín Gamarra y Antonio Gutiérrez de la Fuente contra José de la Mar en 1829:

«La facción que ha rodeado exclusivamente a los encargados del ejercicio de Poder ejecutivo, no sólo han cometido el crimen de haber infructuosas sus rectas intenciones sino que los ha arrastrado a imprudencias y desaciertos que altamente han comprometido el honor y la seguridad de nuestra Patria» (El Republicano [Arequipa], 20 de junio de 1829).

La contrapartida a la argumentación expuesta es una larga y continua reflexión sobre la cultura revolucionaria peruana. Se trata de responder a las siguientes preguntas: ¿Cómo establecer un sistema constitucional a partir de un acto de quebrantamiento de la legalidad jurídica? ¿Cómo poner fin al mundo de las revoluciones y de los caudillos, y establecer el orden y la libertad? Son preguntas presentes en todos los caudillos y políticos del Perú decimonónico. Parte de la explicación de la cultura revolucionaria reside en el dominio de las pasiones, los intereses y el «espíritu de partido» entre los revolucionarios. Un editorial del Atalaya del año de 1833 se queja de que «las pasiones son el origen de los males de la sociedad». Continúa diciendo que «Algunos peruanos enemigos de la patria» están dominados por ellas. Esta cultura marcada por la división destruye el «bien público». El editorial se pregunta:

«iCuándo harán, sin divisiones, feliz la familia del suelo de Manco? Hay un partido de hombres temerarios que trabajan por la caída del presidente».

En el artículo se nota la idea fuerza de que el espíritu de partido y, sobre todo, de facción, sustenta una cultura revolucionaria que impide la estabilidad del sistema republicano. El diagnóstico es sencillo y la cura es clara: hay un «fatal espíritu de facción y de anarquía» que requiere ser extirpado (La Miscelánea (Lima), «Encomienda la revolución», n. ${ }^{\circ}$ 523, 30 de marzo de 1832).

\section{DE 1850 A 1870}

Las elecciones para Presidente de 1851 reformulan los discursos y prácticas políticas, en particular porque están situadas en un nuevo contexto en que los clubes electorales juegan un rol más que relevante, un fenómeno recurrente 
también en otros países de Hispanoamérica a mediados del siglo XIX. Hay un afianzamiento de las organizaciones políticas en la escena, en particular los clubes electorales, que cubren buena parte del territorio nacional, continuando a la vez con fuerza las tertulias de intelectuales, un elemento forjador de la opinión pública (Peralta, 2003: 85-87). En realidad, es un hecho decisivo para las elecciones de 1851 el que éstas se remitan a toda una cadena de clubes. En ese contexto juega un rol significativo un grupo de periódicos que harían de voceros de los clubes. Lima sería el centro de operaciones de dichas organizaciones. Destacan el diario El Progreso, por el lado de la campaña de Domingo Elías, y también El Rímac, por el de su opositor, Rufino Echenique. Mucho de lo escrito en dichos periódicos era repetido por sus similares en provincias, formándose una cadena de organización y de generación de imágenes con una estructura y, lo que es más interesante, con la figura de un discurso claro de un candidato como representante de una organización (Loayza, 2005). Con los clubes y los periódicos aparece con claridad la noción de «candidato».

Acerquémonos ahora a las campañas en las que se van configurando las imágenes de los candidatos en 1851. Detengámonos en la campaña de prensa del rico hacendado e importador de chinos, Domingo Elías, candidato del Club Progresista. Elías empieza la construcción de su imagen como candidato una vez concluida la elección parroquial. Se inicia con una curiosa campaña en El Progreso. Los editoriales del diario juegan con la imagen de representar el punto de vista de hombres de ideas, de gente pensante que no se adscribe al culto de una figura providencial. La visión de programa es uno de los temas centrales de la campaña. En esto último podemos reconocer una táctica de imagen que sería común en la política de tiempos posteriores. En contraste con la campaña de Elías tenemos la del grupo de Echenique, cuyo órgano de difusión es el diario El Rímac, al que debemos sumar un grupo de periódicos satélite de provincias. Lo favorece la Sociedad de Fraternidad y Unión Electoral, que tiene vínculos en diversas ciudades del país. Los círculos opositores a la candidatura de Echenique tipifican a sus adherentes como gente «comprada», o califican a los miembros de su club como «mandingos», en clara alusión al origen africano de sus integrantes (Mc Evoy, 1997: 68-69). Los diarios del grupo de Echenique en cambio enfocan la construcción de la imagen de su candidato sobre la base de una crítica del plan de gobierno de sus rivales. El Rímac se inclina así por exaltar la experiencia del General y su obediencia a la Constitución, aunque tiene como elemento fundamental la crítica a la estrategia de imagen del Club Progresista, a cuyos miembros señala despectivamente como una partida de empresarios que representan el lucro personal y la búsqueda mezquina del interés privado (Loayza, 2005).

La década de 1850 es rica en debates ideológicos. La revolución de 1854 tuvo una impronta liberal que se plasmó después en la constitución de 1856. Dicha carta da testimonio de los cambios en la percepción sobre las asociaciones en términos positivos. De acuerdo a Alex Loayza, la constitución de 1856 fue la primera en aceptar normativamente las asociaciones como parte constituyente de la sociedad (Loayza, 2009: 398). En el artículo 28 de la carta de 1856 se dice que:
«... todos los ciudadanos tienen el derecho de asociarse pacíficamente, sea público o en privado, sin comprometer el orden público».

En 1858, Francisco de Paula González Vigil, sacerdote, liberal, crítico al poder del Papa y excomulgado varias veces, escribió un conjunto de artículos en el diario El Constitucional, que los republicó posteriormente en El Pueblo en 1864 y El Correo de Perú en 1871-1872 alabando a las asociaciones, a las que define como «comunidad de intereses y mutuos oficios» (González Vigil, 1970 [1858: 27). Las asociaciones son parte de la condición humana. Estas eran parte fundamental de la sociedad civil. En un gobierno «democrático, las asociaciones políticas no deben ser percibidas como amenazas; sino como parte de la participación ciudadana y es beneficioso a la república». Para el sacerdote liberal, era un absurdo que la política fuera monopolio del gobierno (González Vigil, 1970 [1858]: 23, 29-33).

En 1862, Santiago Távara publica por partes en El Comercio «La Historia de los Partidos». Este se inicia con San Martín y continúa hasta 1862. Su texto es una suerte de recuento de la historia y reflexión de la política republicana desde una óptica liberal y creyente del progreso humano. Es un progreso vinculado al gobierno democrático, civil, cristiano y con fuertes tintes igualitarios y anti-aristocráticos.

Concibe la política como una lucha de partidos ideológicos sin que necesariamente los actores históricos se reconocieran a sí mismos o se les designara de tal modo (una imagen del pasado que continúa hasta nuestros días). Comparando el Perú con Europa, Távara dice:

«Apenas hacen cuarenta años y ya somos muy superiores a los de la época del Rey y vamos adelante (Távara, 1951 ([1862]: 5)».

Para Távara hubo dos grandes «partidos»: los liberales «que querían orden y responsabilidad, según la ley y los militares, y togados que habían crecido bajo la férula de los subalternos de Fernando VII y Carlos IV». Bartolomé Herrera formó la identidad conservadora bajo la supremacía del principio de autoridad. Mucho de los que los conservadores reclamaban era «la autoridad de Herrera disfrazada» (Távara, 1951 [1862]: 7).

Los «partidos» se vinculan con corrientes ideológicas. En la década de 1860 se reconoce la existencia de un llamado partido liberal. Hay una suerte de organización alrededor de él. El 10 de julio de 1861, «el partido liberal» reunió «más de mil ciudadanos... se les había preparado un lúcido banquete en el que reinó el orden y armonía: los brindis, solo fueron por el triunfo de su candidato». En el discurso se «llamó a la unión y a la concordia a todos sus hermanos extraviados por la falacia y el engaño [...]. La causa que sostenemos, es la del pueblo, es la del Perú, es la de la patria» (EL Comercio, «Comunicados. Intereses Generales», 11 de julio de 1861). Sin embargo, los seguidores del candidato liberal, General D. Ramón López Lavalle, creían que debían «obrar en consonancia con los principios». Con «la victoria solemne de la voluntad popular y acto continuo la fusión de todos los partidos» (Comunicados. Intereses Generales, 2 de julio de 1861); es decir, los partidos deben tender a la unidad después del enfrentamiento electoral.

Los cambios semánticos mencionados implicaron una nueva etapa en cuanto a las prácticas políticas con organizaciones estructuradas y con una clara plataforma 
pública. Sin embargo, ello no quiere decir que la búsqueda de la unidad y la crítica a la división no persista. El cambio no es una tabula rasa: un nuevo inicio dejando de lado antiguas concepciones. Hay una ambivalencia con el concepto partido en torno al clamor por la unidad o de la pluralidad. Era común la crítica al espíritu de partido como causa de las revoluciones. En 1860, Francisco Alvarado, Prefecto de Amazonas, declara a los pueblos bajo su mando en momentos de elecciones: ciudadanos «al tiempo de ejercer vuestra soberanía popular, no os desfraternice el espíritu de partido que tantos estragos acarrea y que ocasiona infinitos males a la patria». Se exhorta a los votantes a tener un comportamiento ejemplar pues no debe repetirse «el escándalo que en las elecciones anteriores, introduciendo cismas, forjando desavenencias y procurando divorciarse unos a otros». En pocas palabras, exige que se forje una unidad política (El Comercio, «Comunicados. Intereses Generales», 2 de enero de 1860). Valga la verdad que las elecciones parroquiales se convirtieron en un campo de batalla en la segunda mitad del siglo XIX. Con la aparición de las organizaciones políticas, las elecciones de primer grado se vuelven fundamentales. Sus electores ya no tendrán «la autonomía» de antes, pues pertenecen a algún grupo políticamente formalizado (Aljovín, 2005: 59-74). Es interesante leer los boletines revolucionarios del General Tomás Gutiérrez del año de 1872. Estos son denuncias feroces a la elección de Manuel Pardo —el primer presidente civil electo- . La candidatura de Pardo fue organizada a partir de la Sociedad Independencia Electoral Nacional. En el año de 1872, los hermanos Gutiérrez, oficiales prominentes del ejército, dan un golpe de Estado fallido para evitar que Pardo asuma la presidencia. Los tres hermanos terminan asesinados y sus cuerpos ahorcados en la catedral de Lima. En momentos en que pensaba que lograría su cometido, Gutiérrez anuncia en un comunicado a sus soldados, los «centinelas de la patria», que han salvado la república e impuesto el orden al sepultar «una facción política que había resuelto adueñarse de la república. No contaban los prosélitos del más desenfrenado absolutismo con vosotros» (El Comercio, «Boletines de los revolucionarios del día 24 de julio de 1872, 27 de julio de 1872»). Ante las acusaciones de ilegitimidad, Manuel Pardo, líder del recién fundado Partido Civil, y sus seguidores, se declaran vencedores de la justa electoral representando a la mayoría del país. Dicen que «los enemigos de la verdad y las falsificaciones de la historia electoral siguen llamando círculo al inmenso partido que elevó a la silla presidencial al actual jefe del Estado». No aceptan la victoria de Pardo, que alcanzó «dos terceras partes de la nación» (El Comercio, 17 de setiembre de 1872).

De igual modo, el Partido Civil, así como otras organizaciones políticas (clubes políticos), son descritos como parte positiva del sistema republicano en la década de 1870. En un sistema parlamentario, «la existencia de los partidos organizados y disciplinados es indispensable, porque es el medio de hacer triunfar las doctrinas que profesan y los intereses a que están ligadas» (El Comercio, 17 de setiembre de 1872). Hay una clara concepción de los partidos como expresión de los intereses y de las doctrinas. Se nota que se va deslizando una idea de partido como la asociación organizada de un grupo de personas con intereses e ideología. Una visión opuesta a la de los hermanos Gutiérrez en torno a las organizaciones que apoyaron a Manuel Pardo.

En un libro en torno al Partido Civilista, Ulrich Mücke sostiene una transformación semántica del concepto de partido y de las prácticas políticas con el advenimiento del Partido Civil durante la década de 1870. Partido se utilizaba para asignar un movimiento político vinculado a una persona. A mediados de 1870, con el asesinato de Manuel Pardo, líder del Partido Civil, «Partido Civil» era una expresión con que se denominaba a un grupo de personas y no a un caudillo o a un conjunto de clubes. De algún modo, se desprende de cierta forma del líder y se asigna la denominación a un cierto aparato. De igual modo, siguiendo la idea de aparato, se nota un comportamiento partidista en el Congreso. En el análisis de la forma en que votaron los diputados en la década de 1870 se aprecia una tendencia a una uniformidad partidaria. Finalmente, hay una serie de ataques contra el Partido Civilista con la imagen de que el Congreso estaba dominado por un partido que buscaba sus propios intereses y no los de la nación. Es interesante leer una declaración de éste de 1878 que describe el juego político como de mayoría y minoría de modo positivo:

«Los diversos intereses sociales y la distinta manera de realizarlos, dan lugar a la existencia de los partidos, que luchan por asumir la dirección de los negocios públicos; y en medio de esa lucha constante que es la vida de los pueblos democráticos, sólo puede imperar la voz de las mayorías. [...] La existencia de diversos partidos no es ciertamente una calamidad para el país, sino, antes bien, el síntoma de que late vigorosa en sus entrañas la vida republicana» (Diario de los debates de la Cámara de Diputados del Perú, Congreso ordinario de 1878, 1: 86 (in Mücke, por publicar).

El discurso de Cesáreo Chacaltana a favor de la candidatura de Manuel Toribio Ureta del 25 de junio de 1871 nos muestra los cambios semánticos del término partido que hemos estado reseñando a partir de la década de 1850. Para Chacaltana, «la república y la democracia llaman por igual a todos sus hijos», de cualquier profesión, para acceder a la presidencia. Los partidos deben «levantar la libertad política de los pueblos sobre el ahogante yugo del despotismo». El orador define luego el rol de los candidatos. Estos «agrupan en torno suyo un sistema de ideas y de principios de gobierno, forman al contrario un núcleo de actividad incesante, único capaz de realizar la ley del progreso a que debe sujetarse toda la sociedad». Con un fuerte discurso antimilitar, sostiene que los oficiales del Ejército han tenido una exagerada presencia en la política. Sugiere que «se restablezca e equilibrio social, y en el poder se hallen representadas todas las esferas». En su defensa de la candidatura de Ureta, se afirma que éste representa «la justicia de todos los partidos, es el símbolo del principio social que todos los partidos aceptan y que es superior al principio de cada partido». De ese modo, puede lograr en un futuro gobierno «conciliar los intereses de los partidos con los intereses nacionales: el que eso hace es el que representa el partido nacional, que es el verdadero PARTIDO CIVIL». Recalca el valor de representar un liderazgo y un partido con ideas, porque 
«sólo los hombres que llevan al poder una misión determinada tienen derecho a exigir a los partidos su apoyo... Y sólo de ese modo los partidarios podrán apartar su confianza cuando les falten a sus promesas. iSólo asî se comprende una soberanía racional!» (El Comercio, «Comunicados. Intereses Generales», 26 de junio de 1871).

En mucho, el discurso debió buscar ocupar espacios similares a los de Manuel Pardo, futuro fundador del Partido Civil. Chacaltana, sin embargo expresa una visión que aceptaba los partidos que debían terminar fusionándose a favor de los intereses de la nación.

No quisiera cerrar el artículo dejando la impresión que una concepción pluralista de partido emergió por los años de 1870, dejando de lado la noción de unidad - que en mucho tiene una mayor fuerza de convocatoria-. Nuestro propósito más bien ha sido mostrar que la tensión unidad/pluralidad es parte fundamental del lenguaje de la democracia instaurada en el siglo XVIII por las llamadas «revoluciones Atlánticas» descritas por Robert Palmer (Palmer, 1989, Tomo I, 3.24). Con mucho acierto, a su modo, François-Xavier Guerra incluyó al mundo hispanoamericano, del cual el Perú es parte, en dicho proceso histórico de cambio radical del lenguaje y de las prácticas políticas en el llamado mundo Atlántico (Guerra, 1992: 115-148). La transformación de la cultura política no implica el abandono de un concepción unitaria para una plural, sino un cambio de relaciones entre una y otra. Como bien lo escribe Pierre Rosavallon, durante los momentos de una fuerte concepción a favor de la unidad en Francia a fines del siglo XVIII e inicios del XIX, la dinámica parlamentaria, los intereses en la sociedad y su aceptación perforaban la unidad o, para utilizar el vocabulario de Juan Jacobo Rousseau, la voluntad general (Rosavallon, 1998). Del otro lado de la orilla, el surgimiento de las organziaciones políticas no borró la ansiedad por fundar un mundo basado en la unidad, dejando de lado los intereses individuales o grupales. La tensión entre unidad y pluralidad persiste hasta nuestros días y es parte constituyente de la democracia. Ejemplo claro de dicha tensión es el discurso de la antipolítica, y el movimiento antipartidario del Perú de la década de 1990 en que se describían a los políticos como representantes de sus propios intereses y no los de la nación.

\section{Referencias citas}

\section{Fuentes primarias}

\section{Prensa}

EL COMERCIO (Lima), 1871 - Comunicados. Intereses Generales, 26 de junio.

EL COMERCIO (Lima), 1871 - Comunicados. Intereses Generales, 2 de julio.

EL COMERCIO (Lima), 1872 - Comunicados. Intereses Generales, 17 de setiembre.

EL COMERCIO (Lima), 1872 - Boletines de los revolucionarios, 24 de julio.

CRÓNICA POLÍTICA Y LITERARIA DEL LIMA, 1827 - 4 de junio.
EL FARO (Tacna), 1843 - A la República, n. ${ }^{\circ}$ 10, 25 de febrero.

EL REPUBLICANO (Arequipa), 1829 - 20 de junio.

EL REPUBLICANO (Arequipa), $1842-22$ de enero.

EL VOTO NACIONAL (Lima), $1835-\mathbf{n} .^{\circ} \mathbf{9 1}, 28$ de febrero.

EL TELÉGRAFO DE LIMA, 1826 - Variedades: Debe un partido ser gobierno, 26 de enero. EL OBSERVADOR, 1833 - Elecciones, $\mathbf{n} .^{\circ}$ 7, 30 de enero.

LA MISCELÁNEA (Lima), 1832 - Encomienda la revolución, n. ${ }^{\circ}$ 523, 30 de marzo.

EL MERCURIO PERUANO (Lima), 1827 - Mercurio Peruano, 31 de diciembre.

Libros

CDIP: COLECCIÓN DOCUMENTAL PARA INDEPENDENCIA DEL PERÚ, 1971-La rebelión de Túpac Amaru: La Rebelión; Lima: Comisión Nacional del Sesquicentenario de la Independencia del Perú, Tomo II, Volumen 2. Edición e introducción de Carlos Daniel Valcárcel.

CDIP. COLECCIÓN DOCUMENTAL DE LA INDEPENDENCIA DEL PERÚ, 1971 - La revolución del Cuzco de 1814; Lima: Comisión Nacional del Sesquicentenario de la Independencia del Perú, Tomo III. Recopilación y prólogo por Horacio Urteaga y Daniel Valcárcel,

DIARIO DE LOS DEBATES DE LA CÁMARA DE DIPUTADOS DEL PERÚ, 1878 - Congreso ordinario de 1878, 1

GONZÁLEZ VIGIL, F. de P., 1973 [1858] - Importancia y utilidad de las asociaciones. Educación y sociedad, 1; Lima: Instituto Nacional de Cultura.

LA ABEJA REPUBliCANA (Lima), 1971 [1822] - Lima: Petróleos del Perú. Prólogo y notas de Alberto Tauro.

PARDO Y ALIAGA, F., 1973 - Poesías de Don Felipe Pardo y Aliaga, 452 pp.; California: University of California Press. Introducción, edición y notas de Luis Monguió.

VIDAURRE, M. L., 1828 - Efectos de las facciones en los gobiernos nacientes: principios fundamentales del gobierno democrático constitucional representativo, 279 pp.; Boston: W. W. Clapp

TÁVARA, S., 1951 - Historia de los partidos; Lima: Editorial Huascarán. Edición y notas de Jorge Basadre y Félix Denegri Luna.

\section{Libros}

ALJOVÍN DE LOSADA, C., 2000 - Caudillos y constituciones: Perú 1821-1845, 354 pp.; Lima: PUCP, IRA, FCE.

ALJOVÍN DE LOSADA, C., 2005 - Sufragio y participación política. Perú 1808-1896. In: Historia de las elecciones en el Perú (C. Aljovín de Losada \& S. López, eds.): 19-74; Lima: IEP.

ANNINO, A. (ed.), 1995 - Historia de las elecciones en Iberoamérica. Siglo XIX, 479 pp.; Buenos Aires: FCE.

BASADRE, J., 1983 - Historia de la república del Perú, 284 pp.; Lima: Editorial Universitaria, Vol. I.

FERNÁNDEZ SARASOLA, I., 2000 - Los partidos políticos en el pensamiento español.

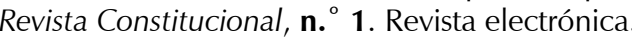

FERNÁNDEZ TORRES, L., 2009 - Partido y facción en España 1780-1870. Manuscrito. 
GUERRA, F.-X., 1992 - Modernidad e independencias: ensayos sobre las revoluciones hispánicas, 406 pp.; Madrid: MAPFRE.

GUNN, J.A.W. 1974 - Influence, Parties and the Constitution: Changing Attitudes, 17831832. The Historical Journal, Vol. 17, n. ${ }^{\circ}$ 2: 301-378.

LOAYZA, A., 2005 - El Club Progresista y la coyuntura electoral de 1849-1851. In: Historia de las elecciones en el Perú. Estudios sobre el gobierno representativo (C. Aljovín de Losada \& S. López, eds.): 395-424; Lima: IEP.

LOAYZA, A., 2009 - Constitución: Perú. In: Diccionario político y social del mundo iberoamericano. La era de las revoluciones 1750-1850 (J. Fernández Sebastián, ed.): 392-400; Madrid: Fundación Carolina, Sociedad Estatal de Conmemoraciones Culturales, Centro de de Estudios Políticos y Constitucionales.

LOAYZA PÉREZ, A. \& ALJOVÍN DE LOSADA, C., 2009 - Federalismo: Perú. In: Diccionario político y social del mundo iberoamericano. La era de las revoluciones 1750-1850. (J. Fernández Sebastián (ed.): 517-524; Madrid: Fundación Carolina, Sociedad Estatal de Conmemoraciones Culturales, Centro de de Estudios Políticos y Constitucionales.

O'PHELAN, S., 1985 - El mito de la «independencia concedida». Los programas políticos del siglo XVIII y el temprano siglo XIX en el Perú y Alto Perú (1730-1814). Histórica, IX/ 2: 155-191.

PERALTA, V., 2003 - Las trampas de la imparcialidad. El Comercio y el gobierno del general Castilla, Perú 1845-1850. Debate y Perspectiva, $\mathbf{n .}^{\circ}$ 3: 85-87.

MC EVOY, C., 1997 - La utopía republicana: ideales y realidades en la formación de la cultura política peruana (1871-1919), 467 pp.; Lima: PUCP.

MÜCKE, U., por publicar - Política y burguesía en el Perú. El Partido Civil antes de la Guerra con Chile; Lima: IFEA-IEP.

PALMER, R., 1989 [1969] - The Age of the Democratic Revolution: A Political History of Europe and America, 1760-1800, vol. 1: 544 pp.; Princeton, New Jersey: University Press.

PORRAS BARRENECHEA, R., 1974 - Ideólogos de la Emancipación; Lima: Milla Batres.

RIVA-AGÜERO Y OSMA, J. de la, 1969 - Paisajes peruanos. In: Obras Completas de José de la Riva Agüero, tomo IX; Lima: PUCP.

ROSANVALLON, P., 1998 - Le peuple introuvable; París: Éditions Gallimard. 